\title{
Considerações sobre a Relação entre Filosofia e Ciência em Alexandre Koyré a partir de uma Questão
}

[Considerations about the Relationship between Philosophy and Science in Alexandre Koyré from one Question]

\author{
Filipe Monteiro Morgadd ${ }^{\star}$
}

\begin{abstract}
Resumo: A partir de uma questão apresentada na "Introdução" deste artigo, procuraremos elucidar a relação entre os pensamentos filosófico e científico conforme escritos de Alexandre Koyré. Dividimos nosso texto em quatro partes, que abordam: (1) a disputa de Koyré contra a filosofia da ciência positivista e a epistemologia de Émile Meyerson, estas duas defendendo a existência de verdades imutáveis; (2) a oposição de Koyré às epistemologias continuistas, apresentando o citado pensador como um descontinuista dado seu diagnóstico da historicidade da razão; (3) a tese koyreana que busca explicar a gênese do matematismo da física clássica como uma ilustração do primado teórico da ciência e da sua descontinuidade; (4) a resposta à questão inicial do nosso artigo, a partir da ideia da inseparabilidade entre filosofia e ciência e da ideia de descontinuidade da razão.
\end{abstract}

Palavras-chave: Alexandre Koyré. Filosofia. Ciência.

\begin{abstract}
Based on a question presented in the "Introduction" of this article, we will seek to elucidate the relation between philosophical and scientific thoughts, according to Alexandre Koyré's writings. We divide our text into four parts: (1) Koyré's dispute against the philosophy of positivist science and Émile Meyerson's epistemology, both defending the existence of immutable truths. (2) Koyré's opposition to the continuist epistemologies, presenting himself as a discontinuist given his diagnosis of the historicity of reason; (3) the koyrean thesis that seeks to explain the genesis of classical physics mathematism as an illustration of the theoretical primacy and discontinuity of science; (4) the answer to the initial question of the article, through the ideas of reason discontinuity and inseparability between philosophy and science.
\end{abstract}

Keywords: Alexandre Koyré. Philosophy. Science.

${ }^{\star}$ Bacharel, licenciado e mestre (bolsista CAPES) em Filosofia pela Universidade Federal Fluminense (UFF). E-mail: filipemonteiromorgado@gmail.com. ORCID: https://orcid.org/0000-0002-2732-7164. 


\section{Introdução}

No artigo que ora lhes apresentamos, abordaremos o pensamento do francorrusso Alexandre Koyré (1892-1964), filósofo e historiador da filosofia, religião e ciência, almejando responder a um inquérito, qual seja: por que Koyré vislumbrou uma descontinuidade na história das ciências já na revolução científica do século XVII? Por dois motivos, a opinião koyreana pode suscitar certa estranheza: (1) quando se fala em corte epistemológico, refere-se a uma fissura na razão científica e (2) "científico" é entendido como algo que só passou a existir a partir do advento da ciência moderna. A fim de dirimir essas razões de estranheza, mostraremos que, conforme o pensamento koyreano, a ciência moderna nasceu deveras no século XVII, mas que a razão científica data de muito antes, já estando presente na filosofia.

A ciência moderna, uma ciência matematizada, teve sua consolidação, de acordo com nosso epistemólogo francorrusso, a partir de uma brusca $m u$ tação intelectual culminada no século XVII. As pesquisas koyreanas atinentes à história das ciências primam pelo período inicial do pensamento científico moderno, em que surge a física clássica 1 . Podemos considerar o referido epistemólogo um racionalista, posto que enfatiza a atuação da matemática na ciência e, no pensamento filosófico, o matematismo; mas, a despeito do racionalismo, ele defenderá que a razão não é terreno habitado por absolutos e verdades imutáveis. As verdades científicas mudam.

Muito embora o imo das investigações koyreanas fosse a ciência moderna em suas origens, o epistemólogo não deixou de compreender, pioneiramente, que a história das ciências deve ser entendida como descontínua (BULCÃO, 2010, pp. 102-103), havendo, já na aurora da ciência moderna, alguma ruptura, fissura na razão. Dado o período que investigava (o início da ciência moderna), Koyré parecia encontrarse em dupla desvantagem na tarefa de efetuar o diagnóstico da descontinuidade do desenvolvimento científico: (1) a primeira e quase óbvia desvantagem ocorre em virtude do epistemólogo francorrusso ter efetuado um pioneirismo e, como todo trabalho pioneiro, trata-se de algo difícil de ser efetivado; (2) a segunda dá-se em razão de seu objeto de pesquisa ser mais a ciência em seu momento originário (século XVII) e não aquela em cujo interior já haviam ocorrido bruscas modificações (a título de exemplo, temos a segunda metade

\footnotetext{
${ }^{1}$ Utilizaremos a mesma nomenclatura de Études Galiléennes (1939), que, ao menos em sua edição de 1966, indica, em nota de rodapé, a expressão "física clássica" para a pré-quântica e para a quântica, "física moderna". Quando falarmos em "ciência moderna", entretanto, estaremos referindo-nos à física clássica e moderna (KOYRÉ, 1966, p. 12), haja vista entendermos que elas têm algo em comum: a ênfase ao matematismo no tratamento do mundo físico. A física clássica ou pré-quântica é a de Galileu, Descartes, Newton, Laplace, etc. e a física moderna, a de Max Planck, Albert Einstein, Werner Reisenberg, etc.
} 
do século XIX e o início do século XX). Ora, se comparado a pensadores cujo objeto de estudo é a ciência moderna já drasticamente modificada, que gozava então de salutares mutações teóricas em relação ao estado inicial da ciência matematizada, o filósofo-historiador francorruso parece encontrar-se em desvantagem na empreitada de diagnosticar a descontinuidade inerente ao progresso científico. Então, inquerimos: qual motivo fez o nosso epistemólogo entender que, já nos primórdios da física clássica, ocorrera uma descontinuidade no interior da racionalidade científica? Por agora, nossa resposta é lacônica: porque ele nunca achou possível separar, de maneira absoluta, a filosofia (e até mesmo a teologia) da ciência, frisando que uma revolução científica está sempre acompanhada de uma subversão filosófica (KOYRÉ, 2011c, p. 264), levando-o a considerar que já ocorrera, na história humana, outras rachaduras na razão, sendo a revolução científica do século XVII uma delas.

\section{Primeira parte: a teoria como primado da ciência}

Acima, valemo-nos de expressões como "teoria", "ideias", "quadro de ideias". Fizemo-lo propositalmente, pois, desde quando iniciou suas pesquisas a respeito da história do pensamento científico, Koyré considerou a ciência como sendo, sobretudo, teoria, atividade in- telectual, expurgando da explicação a respeito da sua gênese a ênfase dada à técnica, ao caráter prático da ciência moderna. Tal consideração possui resultados, sendo um deles a consideração de que, em ocorrendo uma mudança no cenário intelectual, abrem-se caminhos a novidades também na ciência, haja vista ela ser uma das suas integrantes. Foi o que ocorreu no século XVII: a ciência moderna foi fruto de uma radical mutação intelectual engendrada por um quadro de ideias produzido pela filosofia. Em Études Galiléennes (1939), Koyré escreve:

Com efeito, o estudo da evolução (e das revoluções) das ideias científicas [...] nos mostra o espírito humano lutando com a realidade; revela-nos seus defeitos, suas vitórias; mostranos qual esforço sobre-humano custou-lhe cada passo sobre a via da intelecção do real, esforço que resultou, por vezes, em uma verdadeira "mutação" do intelecto humano; transformação graças àquelas noções, às penas "inventadas" pelos maiores gênios, tornadas não somente acessíveis, mas ainda fáceis, evidentes para os estudantes (KOYRÉ, 1966, p. 11).

Na nota 6 do artigo "Galileu e Platão" (1943), assevera-se: "A ciência de Descartes e de Galileu foi, bem enten- 
dido, extremamente importante para o engenheiro e o técnico. Afinal, ela provocou uma revolução técnica. Entretanto, não foi criada e desenvolvida nem por engenheiros, nem por técnicos, mas por teóricos e filósofos" (KOYRÉ, 2011e, p. 166). O tom do "Prefácio" à obra Do Mundo Fechado ao Universo Infinito (1957) não é diferente: considerando rasas as interpretações que propunham explicar a revolução científica do século XVII a partir de uma "suposta conversão do espírito humano da teoria para a praxis, da scientia contemplativa para a scientia activa et operativa, o que transformou o homem de espectador em proprietário e senhor da natureza" (KOYRÉ, 2006, p. 1), Koyré fala em "mudança espiritual", em "quadro de ideias". Assim, podemos notar que o historiador-filósofo salienta o caráter teórico para explicar as origens da ciência moderna, não o seu cariz prático, ativo, técnico e tecnológico; isso porque sustenta que a técnica, o poder prático da ciência, não é senão criação da própria ciência, sendo esta a possi- bilitadora da tecnologia e da técnica tal como se configuram na Modernidade. A física clássica não se confunde com a técnica, embora esta seja uma marca sumária daquela. A ciência moderna aperfeiçoou a técnica e promoveu a tecnologia. Os engenheiros não guiaram Descartes e Galileu; estes encetaram o caminho que aqueles deveriam seguir.

Havia ciência na Antiguidade e na Idade Média, mas não nos moldes modernos. Uma acentuada modificação no quadro das ideias ocorreu, forjada por filósofos, teólogos e - se assim já os podemos denominar - cientistas, acarreando o surgimento do que conhecemos como "ciência moderna" ou "física clássica", abjurando o pensamento científico antigo e medieval, erigindo novos padrões de racionalidade. Quando Koyré dá primazia à teoria, vai de encontro aos positivistas, refratando tanto o ímpeto empirista deles quanto as suas consequências, como o menosprezo e/ou a aversão direcionados à influência dos pensamentos filosófico e religioso sobre a ciência. Conforme

\footnotetext{
2"Koyré critica a leitura positivista da história do saber científico. Mostra que o pensamento científico não se separa do pensamento filosófico, pois não se desenvolve no vácuo, mas sim no interior de um sistema de ideias" (BULCÃO, 2010, p. 99). "Se eu tivesse tomado inteiramente ao pé da letra o título de minha comunicação - as cosmologias científicas, isto é, aquelas que levam às últimas consequências a separação e, portanto, a desumanização do cosmo -, não teria, verdadeiramente, grande coisa a dizer, e teria tido de começar imediatamente com a época moderna, provavelmente com Laplace. Quando muito teria podido evocar, à guisa de pré-história, as concepções das primeiras épocas da astronomia grega, a de Aristarco de Samos, de Apolônio, de Hiparco, porque as concepções cosmológicas, mesmo as que consideramos científicas, só muito raramente - quase nunca, até - foram independentes de noções que não o são, ou seja, de noções filosóficas, mágicas e religiosas. Mesmo para um Ptolomeu, mesmo para um Copérnico, mesmo para um Kepler, e mesmo para um Newton, a teoria do cosmo não era independente daquelas noções. Portanto tomei 'cosmologias científicas' num sentido mais amplo, capaz de englobar as doutrinas dos pensadores que acabo de citar” (KOYRÉ, 2011a, p. 83, grifo nosso). Aliás, por falar em Laplace: "[...] o determinismo, como se diz a partir do século XIX, é ao mesmo tempo estrito e universal. Ele manifesta-se numa passagem famosa de Laplace, que o liga expressamente ao princípio de razão suficiente, apresentado como evidente. Ele estabelece uma ligação estreita entre determinismo e previsibilidade. E nota-se que esta requer, por um lado, o conhecimento das leis da mecânica e o domínio do aparelho matemático adequado, por outro, a medida precisa e exacta das condições iniciais que são de duas espécies, umas de ordem mecânica, outras de ordem geométrica” (BLANCHÉ, 1983, p. 75, grifo do autor).
} 
entendiam os positivistas, tudo o que era filosófico e religioso configurava-se como entrave ao progresso científico ${ }^{2}$. No século XIX e início do XX, a filosofia da ciência positivista era majoritária nas universidades, com algumas exceções importantes, como Poincaré e De Broglie (MOLES, 2010, p. 4). O que os positivistas tomavam por caro à ciência, com efeito, eram os fatos sensíveis, as coisas brutas observáveis empiricamente. Ora, o epistemólogo francorrusso, ainda no "Prefácio" de Do Mundo Fechado ao Universo Infinito (1957), frisa que "A ciência, a filosofia e até mesmo a teologia mostram interesse legítimo por questões sobre a natureza do espaço, a estrutura da matéria, os padrões de ação e, last but not least, sobre a natureza, a estrutura e o valor do pensamento e da ciência humana" (idem, pp. 2-3).

Koyré compreende, em suma, que, para entender o surgimento da ciência moderna, não se pode separá-la da filosofia e dos debates teológicos, que criaram uma ambiência intelectual da qual a ciência é, "a um só tempo, raiz e fruto" (ibidem, p. 1). A cisão nítida e absoluta entre filosofia e ciência é impensável. Estabelecer fronteiras que separassem a ciência da filosofia seria um ato bastante arbitrário, pois essas disciplinas são, em certo grau, simbióticas. Por essa razão, Marlon Jeison Salomon salienta que

Se é apenas a partir da década de 1930 que ele [Koyré] irá se tornar historiador do pensamento científico, não se pode desconsiderar que em sua maneira de escrever esta história tal dissociação [entre filosofia e ciência] nunca será sustentada - o que não significa dizer que Koyré advogue contra a afirmação da autonomia da ciênciaß ${ }^{3}$, Na Introdução ao primeiro dos três ensaios redigidos na segunda metade dos anos 30 e reunidos em 1939 sob o título Études galiléennes encontramos implicitamente esta ideia: o nascimento da ciência moderna não corresponde a um momento de cientifização do mundo, de purificação do espí-

\footnotetext{
Partindo disso que Blanché explica, fica clara a razão da crença laplaciana em uma inteligência divina capaz de saber a respeito de tudo (inclusive passado, presente e futuro, simultaneamente): "Devemos, pois, encarar o estado presente do Universo como o efeito do seu estado anterior e como causa do que vai seguir-se. Uma inteligência que, por um instante dado, conhecesse todas as forças de que está animada a natureza e a situação respectiva dos seres que a compõem, e que, além disso, fosse ampla o bastante para submeter seus dados à análise, abarcaria na nossa fórmula os movimentos dos maiores corpos do Universo e os do mais leve átomo: nada seria incerto para ela, e o futuro, como o passado, estaria presente aos seus olhos" (LAPLACE apud BERGÉ; POMEAU DUBOIS-GANCE, 1996, p. 30). Talvez, a ideia laplaciana dessa inteligência não tenha contribuído para a construção da ciência de Laplace, mas é certo que as noções de determinismo e previsibilidade (esta associada àquela (BLANCHÉ, 1983, p. 75), noções depois consideradas de cunho um tanto fideístico e, consequentemente, abandonadas na segunda metade do século XIX (idem, p. 75)) foram de imponente influência sobre a formulação do pensamento científico do astrônomo francês.

3 “O que não significa, bem entendido, que eu pretenda negar a importância da descoberta, dos fatos novos, nem a da técnica, nem tampouco a autonomia e até mesmo a autologia do desenvolvimento do pensamento científico” (KOYRÉ, 2011c, pp. 264-265).
} 
rito científico ao cabo da longa e taciturna noite da Idade Média, de estabelecimento das corretas e verdadeiras leis que regem os fenômenos físicos, mas sim a uma "profunda transformação intelectual”, a uma mutação da atitude intelectual que caracterizava o pensamento científico antigo e medieval, ou, mais precisamente, a uma transformação dos próprios marcos sobre os quais o pensamento até então se assentava. [...] Em passagens decisivas sobre todos os debates que, de Copérnico a Galileu, tornaram possível a emergência da noção de sistema mecânico da realidade e de uma física matemática, Koyré afirma sem demora: "não é de um simples problema de ciência, é de um problema filosófico que se trata ao longo de todo este debate"; ou ainda: "é de filosofia, de ontologia, de metafísica que se trata ao longo de todo este debate. Não de ciência pura" (SALOMON, 2010, pp. 75-76).

Privilegiando o aspecto teórico da ciência, Koyré rompe com a epistemologia vigente em seu tempo. Assim, torna-se possível mostrar que a partir da física clássica a ciência não visa ao mundo empírico tal como ele é, experienciando as coisas brutas, acessíveis empiricamente, e doravante formando o saber científico, mas sim depurando o mundo mediante teorias, sendo marcante na ciência moderna o espectro teórico do matematismo, que, por sua vez, somente pôde realizar-se em virtude de uma mudança no quadro de ideias sobre a natureza do espaço na física, em que o espaço aristotélico do Cosmos foi substituído pelo universo infinito (o que veremos melhor adiante). Essa mudança ensejou em Koyré a ideia de que não há absolutos, sendo perecíveis até os axiomas e os fundamentos do pensamento, demonstrando desse modo que a razão é histórica e que, por conseguinte, a história das ciência é marcada pela mudança, sendo esculpida pela descontinuidade, fazendo o desenvolvimento da ciência repleto de rupturas teóricas.

\section{Segunda parte: a história das ciências é descontínua}

Abordamos, brevemente, a filosofia da ciência dos positivistas. Gostaríamos de chamar atenção, outrossim, para o círculo meyersoniano (este último integrado, durante certo tempo, também por Koyré) de epistemologia, especificamente para salientar que tanto os positivistas quanto os meyersonianos anelavam encontrar absolutos, estabelecer conhecimentos perenes, afastando da ciência qualquer efemeridade. A epistemologia de Meyerson distinguise da dos pensamento positivista; en- 
tretanto, entre ambos há uma comunidade que se dá em torno da esperança nos absolutos?. Koyré, por seu turno, faz declinar a ideia da existência de absolutos da razão. Sem absolutos, não há possibilidade de uma história epistemológica continuista, posto que cai por terra o entendimento consoante o qual a ciência sempre se desenvolveria sobre uma base imutável formada por verdades perenes, pois essa não há, esvaindo-se de tempos em tempos. Entre os positivistas e a epistemologia meyersoniana, portanto, o desenvolvimento da ciência dar-se-ia por acúmulo de conhecimento, assentando-se sobre o mesmo solo e como se ela fosse um só edifício, obra una, cujos construtores/colaboradores fossem os cientistas. Porém, o filósofo francorrusso frustra o desejo daqueles. Doravante, ciência não é um caminho tão seguro quanto se supunha outrora.

\section{[...] a modalidade do saber que se distinguiu ao longo do século}

XVII a partir da física galileana não se inscreve em continuidade com os saberes que a precederam. A física que surge então não é o prolongamento da física do Renascimento ou da Idade Média. A astronomia moderna não é uma continuação da astronomia assíria, indiana ou chinesa. Existe um corte epistemológico entre as ciências antigas e as ciências novas, que inauguram um novo regime de saber. Esse novo saber é o que Lacan, depois de Koyré, chama de "A ciência", que qualifica como "moderna" por distinguila da episteme antiga (GAULT, 2015, p. 156).

A filosofia koyreana, ao frisar a ruptura, o conflito de ideias científicofilosóficas do qual umas saim vivas e outras, mortas, contrapor-se frontalmente à leitura da história das ciências vigente em seu tempo, cujos apologis-

\footnotetext{
4"A preocupação de afirmar os absolutos da razão perpassa, pois, a obra meyersoniana e torna-se evidente quando este [Meyerson] afirma: 'Desembaraçamo-nos de tudo o que é relativo nas diversas observações para alcançar o absoluto, representado aqui por uma distância. Todos os observadores estudarão o mesmo espaço geométrico e é neste contexto que serão estabelecidos, de uma vez por todas, os fenômenos físicos. Aí está uma afirmação importante que nos mostra até que ponto o processo de pensamento ao qual obedecem os relativistas está de acordo com o cânone do intelecto humano que constitui não somente a ciência mas também o mundo do senso comum. Com efeito, este mundo de invariantes absolutos, colocado no contexto eterno do espaço, não somente o mundo da mecânica de Galileu e de Descartes, mas é ainda aquele da nossa percepção imediata'” (BULCÃO, 2010, p. 101, grifo do autor).

5 “Alexandre Koyré ficou famoso por sua história das revoluções científicas que se volta para as transformações ocorridas nos séculos XVI e XVII. Pode-se dizer que o caráter singular da sua obra histórica é sua ruptura com toda uma perspectiva positivista e evolucionista, dominante no campo dos estudos históricos, seja no da história das ideias, assim como, no das ciências" (BULCÃO, 2010, p. 99). "Na verdade Koyré foi levado aos estudos de história das ciências pelo círculo de pesquisas meyersonianos, do qual fez parte durante algum tempo e que dominava o contexto sorboniano da época, início do século XX. Acreditamos, entretanto, que Koyré não se manteve fiel ao mestre, na medida em que uma profunda diferença os separa" (idem, p. 100). Na sequência do artigo de Marly Bulcão, esse "acreditamos" demonstrar-se-á ser um eufemismo, dado que se provará a cisão entre a epistemologia koyreana e meyersoniana, gizando suas fronteiras, sobretudo no aspecto da apologia (Meyerson) ou oposição (Koyré) da/à existência de absolutos racionais.
} 
tas eram positivistas e filósofos como Émile Meyerson ${ }^{5}$, Estes conferiam ao desencadeamento histórico das ciências um caráter contínuo, não havendo rupturas. Atinente a essa concepção, as ciências desenvolver-se-iam por acúmulo de conhecimentos e não por oposição de ideias. Assim entendido, a ciência de Einstein seria um desenvolvimento, um prolongamento, uma continuidade da ciência de Galileu, Descartes, Newton... A ênfase no cariz intelectual da ciência somado ao diagnóstico do declínio de absolutos leva nosso epistemólogo a entender que o intelecto, a razão humana, é maleável. Por conseguinte, a ciência, como expressão da racionalidade, também o é. Maleável, histórica, a razão desenvolver-se-ia, portanto, ruptilmente; a descontinuidade seria imprescindível a todo progresso científico. Agora, razão e descontinuidade não são opostas, sendo esta uma característica relevante daquela, cuja presença faz-se indispensável ao desenvolvimento da racionalidade.

No século XIX, Lobachewsky demonstrou que a soma dos ângulos internos de qualquer triângulo retângulo ordinário é igual a uma medida menor do que a soma de dois ângulos retos, eclodindo, desse modo, a verdade eterna ${ }^{6}$ que supostamente continha a afirmativa "a soma dos ângulos internos de qualquer triângulo é igual à soma de dois retos". Tratou-se de clara ruptura; outras mais não deixaram de ser notadas por nosso epistemólogo francorrusso. Entretanto, Koyré salientara a filosofia e suas relações com a ciência para diagnosticar a descontinuidade da ciência e, de forma mais geral, da razão. Desse modo, nosso epistemólogo inaugura um novo entendimento do que seria a razão. Esta, antes entendida como morada do necessário, do imutável, habitada por absolutos, agora se torna arena de ideias mais ou menos

\footnotetext{
${ }^{6}$ Aqui, temos em mente, sobretudo, Descartes, que afirma, em carta a Marin Mersenne (1588-1648) escrita em Amsterdam e datada de 15 de abril de 1630: "Mas eu não deixaria de tocar, em minha física, várias questões metafísicas e particularmente esta: que as verdades matemáticas, as quais vós nomeais 'eternas', foram estabelecidas por Deus e em dependência inteiramente [dEle], bem como todo o resto das criaturas." (ADAM TANNERY, 1897, v. 1, p. 145, tradução nossa). Diz, ainda: "[...] Deus que estabeleceu essas leis na natureza, assim como um rei estabelece leis em seu reinado" (idem, p. 145, tradução nossa). De Amsterdam, escreve ainda em carta ao mesmo destinatário, na data de 27 de maio de 1630: "Vós me demandais in quo genere causae Deus disposuit aeternas veritates [por qual gênero de causalidade Deus formou as verdades eternas]. Eu vos respondo que é in eodem genere causae [pelo mesmo gênero de causalidade] que ele criou todas as coisas, isto é, ut efficiens totalis causa [como causa eficiente e total]. Pois é certo que ele é também tanto autor da essência como da existência das criaturas: ora, essa essência não é outra coisa senão essas verdades eternas, as quais eu não concebo emanando de Deus senão como os raios, do Sol; mas eu sei que Deus é autor de todas as coisas, e que essas verdades são alguma coisa, e por conseguinte que Ele é o autor [delas]" (ibidem, pp. 151-152, tradução nossa). "E creio que seja o mais considerável aqui que encontre em mim inúmeras ideias de coisas que, mesmo se não existirem em parte alguma fora de mim, não se pode dizer, porém, que não sejam nada. Embora elas sejam pensadas por mim, de certo modo, segundo meu arbítrio, não são contudo uma ficção minha, pois têm suas naturezas verdadeiras e imutáveis" (DESCARTES, 2013, p. 135). "[...] uma verdade eterna [...] tem o seu lugar no pensamento e à qual chamamos noção comum ou axioma: como quando se diz que é impossível que uma coisa seja e não seja ao mesmo tempo, que o que foi feito não pode ser feito de novo, que aquele que pensa não pode deixar de ser ou existir enquanto pensa, e muitas outras semelhantes que seria demorado enumerar (pois são apenas verdades e não coisas que estejam fora do pensamento, e destas há um número muito grande)" (DESCARTES, 1997, p. 44). A metafísica e a epistemologia (inseparáveis, no pensamento cartesiano) sustentam verdades eternas e imutáveis. Como visto imediatamente acima, obras cartesianas de juventude e maturidade atestam-nos isso.
} 
necessárias cujas existências podem estar presentes em apenas alguma fração do tempo histórico. A morte agora invade o território do imortal. A característica telúrica prevalecente do solo das ciências é a movedicidade. O desvanecer avizinha as verdades eternas que ainda não morreram (SALOMON, 2011, p. 4$)^{7}$.

Uma boa ilustração desse embate de ideias e da sobrevivência e morte de algumas se apresenta, justamente, nos séculos XVI e XVII, quando da revolução científica de então. Koyré considera a ciência antiga e medieval muito coerente. Composta por explicações bem encadeadas, sistemáticas e por argumentos convincentes em razão de coadunarem bem com a experiência comum, corriqueira, ordinária, do dia a dia, a ciência pré-moderna usufrui de alto grau de coerência e poder de convencimento. Muitas de suas afirmações parecem evidentes. Confrontada por ideias opostas aos seus alicerces teóricos, o pensamento científico antigo e medieval realiza um forte combate. Com efeito, quem sai vitorioso desse embate é o quadro de ideias fundante da ciência moderna. No entanto, no momento em que se fortaleceram questionamentos à ciência pré-moderna, seu ideário estava consolidado há cerca de um milênio e meio, desde, pelo menos, Aristóteles. Foi bem áspera a via do estabelecimento de novos alicerces racionais, tanto política (o que não abordamos aqui) quanto teoricamente.

\section{Terceira parte: a explicação koyreana para a gênese da física clássica}

A fim de exemplificar a ênfase à teoria e a ruptura presentes na epistemologia koyreana, exporemos a tese de Koyré, que explica a revolução científica do século XVII. Nossa exposição será lacônica, sendo apenas suficiente para nossa finalidade atual. O filósofo-historiador trabalhou, em diversas obras, a tese abaixo apresentada, como em "Galileu e Platão", Estudos Galilaicos (1939), entre outras, sobremodo em Do Mundo Fechado ao Universo Infinito (1957).

Em consonância com o pensamento koyreano, o mais importante que ocorrera na supracitada revolução foi a matematização do mundo, que se configurou como a revolução teórica de então, exarando novos padrões racionais. $\mathrm{O}$ que significa essa matematização? Essa questão faz-se salutar. Diferente do que entendiam os positivistas, a matemática produz um real, não se limita ao simples papel de qualificar quantitativamente os dados sensíveis oriundos da realidade:

\footnotetext{
7 “[...] o que é a história, especialmente a história do pensamento científico ou técnico? Um cemitério de erros, ou até mesmo uma coleção de monstra relegados com razão ao quarto de despejos bons apenas para um canteiro de demolição” (KOYRÉ, 2011c, p. 265, grifo do autor).
} 
Na doutrina de ciência formulada por Koyré (1979, 1982b, 1991), a ciência é definida pelo processo histórico de formalização do real, e não pela quantificação dos dados da experiência. Essa doutrina, fundamentada na teorização, na matematização do real, localiza o experimento como materialização da teoria, e não como quantificação da experiência sensível (LIMA FERREIRA, 2015, pp. 40-41).

Eis o verdadeiro matematismo, que se configura como o que há de revolucionário na ciência que emerge no século XVII. O epistemólogo francorrusso visou explicar a mencionada revolução, verdadeira ruptura racional, inquerindo a respeito do que teria levado pensadores - a exemplo de Galileu e Descartes - a matematizarem o mundo. O que tornou possível pensar o mundo de forma matematizada? O que possibilitou a matematização do mundo? Quais foram as condições originárias do matematismo da física clássica?

No artigo "Da Influência das Concepções Filosóficas sobre a Evolução das Teorias Científicas" (1954), Koyré caracteriza, grosso modo (pois já o fizera em seus pormenores em outros escritos), sua explicação da revolução científica do século XVII pelos seguintes traços: a. Destruição do Cosmos, ou seja, a substituição do mundo finito e hierarquicamente ordenado de Aristóteles e da Idade Média por um Universo infinito, ligado pela identidade de seus elementos componentes e pela uniformidade de suas leis; e

b. Geometrização do espaço, ou seja, substituição do espaço concreto (conjunto de "lugares") de Aristóteles pelo espaço abstrato da geometria euclidiana daqui para frente considerado como real (KOYRÉ, 2011c, p. 266).

Quando consideramos o espaço concreto aristotélico, jamais podemos pensar em uma física matematizada. $\mathrm{Na}$ física aristotélica, o matematismo é impossível. Ilustremos nossa afirmativa com o princício da inércia. Ele, bem entendido, configura-se como matemático; por quê? O espaço da física aristotélica e da Idade Média identificase com o da vida comum, ordinária, o da experiência sensível, no qual nenhum corpo realiza um movimento tal qual descrito por essa lei física da Modernidade. Fato é que ninguém teve qualquer experiência com um corpo que, lançado, moveu-se retilínea e uniformemente; todo corpo arremessado dirige-se, gradativamente, ao solo que, 
para Aristóteles, era o lugar natural do objeto pesado jogado e o trajeto que faz o seu movimento seria prova disso. Quando habitante do espaço concreto, nenhum corpo é inerte plenamente: diagnóstico preciso dos gregos, dentre os quais destacamos Heráclito e Aristóteles. Qualquer objeto existente no mundo empírico perece, dado que todos são perecíveis, mortais.

Mas, e se pensarmos a partir de um espaço no qual podemos cogitar forças idênticas em direção e diametralmente opostas no sentido, anulando absolutamente as forças? Ou se pensarmos, ainda, em um espaço no qual possa não haver forças (o que é, na prática, o mesmo do acima cogitado, pois se tenho forças com direções iguais e diametralmente opostas, o valor é zero, força nula)? Esse espaço teórico, "irreal", encontramos na geometria de Euclides. Doravante, com o espaço euclidiano, abrem-se caminhos para o pensamento. Agora, podemos raciocinar a partir de um espaço completamente diferente do espaço aristotélico. Podemos ensaiar racionalmente corpos movendo-se no espaço euclidiano, um espaço matemático, ou melhor, geométrico. Aqui, perecimento e errância das trajetórias de objetos estão sob o controle da razão. Torna-se possível pensar em um corpo que não perece, bem como em um movimento que não se modifica, exceto com a atuação de outras forças. Possibilitou-se, assim, fazer uma matemática dos corpos pesados que habi- tam o mundo sublunar, dos corpos perecíveis que, "postos" racionalmente no espaço euclidiano, adotam características matemáticas, como a necessidade e a universalidade válidas dentro de um sistema matemático. No espaço de Euclides, um corpo e seu movimento podem conservar-se por toda a eternidade, como a verdade - à época tomada como eterna - da afirmação "a soma dos ângulos internos de um triângulo é igual a $180^{\circ}$ " ou " 2 mais 2 é igual a 4 ".

Imaginando assim o mundo empírico, fez-se declinar a cisão entre mundo supralunar e mundo sublunar, pois se torna possível fazer-se matemática do movimento dos seus corpos pesados como dos daquele já o era. A astronomia torna-se disciplina integrada à física nascente. A substituição do Cosmos pelo universo infinito "determina a fusão da física celeste com a física terrestre, que permite a esta última utilizar e aplicar a seus problemas os métodos matemáticos hipotéticodedutivos desenvolvidos pela primeira" (KOYRÉ, 2011d, p. 198, grifo do autor). Doravante, as leis que regem este mundo regem também aquele. Na verdade, morre a ideia da existência desses dois mundos, desse Cosmos, hierarquicamente ordenado, sendo substituída pela de universo infinito. Portanto, o espaço da nova física acolheu uma importante característica do espaço euclidiano: a homogeneidade.

Vale fazermos uma observação atinente ao caráter experimental da ciên- 
cia moderna, tanto evocado pelos partidários da teoria conforme a qual a física clássica é oriunda da substituição da atitude espiritual da vida contemplativa pela da vida ativa. O que se chama "experiência" (nossa opinião é que o termo "experimento", nesse contexto, faz-se mais adequado), em termos de física clássica, difere drasticamente da "experiência" do cotidiano e da ciência de Aristóteles, em virtude do ímpeto daquela ser matemático.

Aliás, devemos acrescentar - e isto determina os traços característicos da ciência moderna que a pesquisa teórica adota e desenvolve o modo de pensar do matemático. Essa é a razão pela qual seu "empirismo" difere toto caelo do da tradição aristotélica: "O livro da natureza é escrito em caracteres geométricos", declara Galileu. Isso implica a circunstância de que, para atingir seu objetivo, a ciência moderna tem de substituir o sistema dos conceitos flexíveis e semiqualitativos da ciência aristotélica por um sistema de conceitos rígidos e estritamente quantitativos. $\mathrm{O}$ que significa que a ciência moderna se constitui substitundo o mundo qualitativo ou, mais exatamente, misto, do senso comum (e da ciência aristotélica), por um mundo arquimediano da geometria tornado real ou - o que é exatamente a mesma coisa - substituindo o mundo do mais ou menos, que é o da nossa vida cotidiana, por um Universo de medida e de precisão. Com efeito, essa substituição exclui automaticamente do Universo tudo o que não pode ser submetido à medida exata (KOYRÉ, 2011f, p. 303, grifo do autor).

Vejamos ainda:

[... ] a história dessa progressão da ciência moderna deveria ser dedicada a seu aspecto teórico, pelo menos tanto quanto a seu aspecto experimental. De fato, como já afirmei, e como bem o expõe a história da lógica das ciências contada por Crombie, não só o primeiro está estreitamente ligado ao último, mas ele domina e determina sua estrutura (KOYRÉ, 2011b, p. 80, grifo do autor).

Se desejamos falar da dicotomia (ou aparente dicotomia) teoria/prática, na física clássica, nem em uma e nem em outra temos a empiria, a experiência ordinária. No âmbito científico moderno, a experiência do senso comum constitui-se como um obstáculo epistemológico. Ademais, na ciência na- 
tural erigida no século XVII, a teoria coordena a prática; o experimento estrutura-se de acordo com o que a teoria instituída pelo matematismo da ciência moderna prescreve.

\section{Quarta parte: uma resposta ao nosso inquérito inicial}

Tendo em vista o que até aqui expusemos, consideramos termos adquirido ferramentas suficientes para respondermos àquela nossa questão inicial, que nos serviu de guia para uma breve exposição de caros aspectos da filosofia e epistemologia de Koyré. Doravante, encontramo-nos preparados para, a partir desses aspectos, apresentar uma resposta ao inquérito proposto na "Introdução".

"O princípio da inércia nos parece perfeitamente claro, plausível e até praticamente evidente" (KOYRÉ, 2011d, p. 199). Entretanto, esse princípio do movimento, hoje compreendido pelas crianças, nem sempre foi evidente e, na verdade, era tomado como impossível. Foram necessários grandes esforços de gênios como Galileu e Descartes para que tal princípio fosse naturalizado. $\mathrm{O}$ esforço foi o de preparar o terreno adequado para germinar o citado princípio do movimento, sendo esse terreno o do matematismo na ciência natural. Tal qual formulado, o princípio da inércia jamais poderia ter sido pensado em um espaço empírico, como apresentado na parte do artigo imediatamente anterior a esta.

Por seu turno, isso nos permite compreender por que a descoberta de coisas tão simples e fáceis quanto, por exemplo, as leis fundamentais do movimento, que hoje são ensinadas às crianças - e por elas compreendidas -, exigiu um esforço tão considerável, e um esforço que, muitas vezes, careceu de êxito para alguns dos espíritos mais profundos e mais poderosos da humanidade. É que eles não tinham de descobrir ou de estabelecer as leis simples e evidentes, mas de criar e de construir o próprio contexto que tornaria possiveis essas descobertas (idem, p. 20, grifo nosso).

Aí é que atua a filosofia e outros ramos do conhecimento que não podemos chamar estritamente de "ciência", ao menos não no sentido que a palavra tomou na Modernidade. O contexto propício ao aparecimento do matematismo, cuja uma das expressões é o princípio da inércia, foi produzido por de-

\footnotetext{
8"Para o autor dos Estudos Galilaicos, o caminho que levou Galileu a matematizar a física se constituía como um acontecimento que transformava radicalmente os fundamentos de nossa ciência e de nossa concepção de mundo no início do século XVII" (SALOMON, 2015, p. 114).
} 
bates filosóficos e até teológicos 8 , Em Do Mundo Fechado ao Universo Infinito (1957) os exemplos são múltiplos. O grande filósofo do fim da Idade Média Nicolau de Cusa (1401-1464) não era um cientista, mas "a ele se atribui em geral o mérito, ou o crime, de ter afirmado a infinitude do universo" (KOYRÉ, 2006, p. 10), contrariando a cosmologia medieval. Além disso, mesmo entre os cientistas, como Descartes, a temática do espaço não é trabalhada somente nas suas obras científicas, mas também em seus trabalhos metafísicos.

O artigo koyreano "Da Influência das Concepções Filosóficas sobre a Evolução das Teorias Científicas" (1954) frisa:

A história do pensamento científico nos ensina portanto (pelo menos eu tentarei sustentar isso):

$1^{\circ}$ Que o pensamento científico nunca foi inteiramente separado do pensamento filosófico;

$2^{\circ}$ Que as grandes revoluções científicas foram sempre determinadas por subversões ou mudanças de concepções filosóficas;

$3^{\circ}$ Que o pensamento científico - falo das ciências físicas - não se desenvolve in vacuo, mas está sempre dentro de um quadro de ideias, de princípios fundamen- tais, de evidências axiomáticas que, em geral, foram considerados como pertencentes exclusivamente à filosofia (KOYRÉ, 2011c, p. 264).

Vínhamos abordando a ideia da inseparabilidade da filosofia e ciência. A citação acima expõe claramente essa noção. A partir dela, podemos entender que uma revolução científica tem acoplada a si uma revolução, subversão, também no ideário filosófico. Por conseguinte, toda revolução científica é também uma revolução filosófica. Quando Koyré salienta, em Do Mundo Fechado ao Universo Infinito (1957), que o debate copernicano era metafísico e ontológico, muito mais que uma simples questão científica, para além de uma temática localizada da física, também põe em relevo a concepção segundo a qual uma revolução científica tem por companheira uma revolução filosófica, asseverando a inseparabilidade de filosofia e ciência.

Doravante, temos uma resposta mais consistente ao nosso inquérito inicial, qual seja: salientando a teoria, o francorrusso notou que a ciência moderna originou-se mediante uma mudança no âmago de ideias filosóficas, teológicas e científicas, evidenciando que os ideários (inclusive seus axiomas, suas bases, seus absolutos) mudam de tempos em tempos e que, portanto, a razão é histórica. A mutação da razão demonstra que a racionalidade é his- 
tórica e que, consequentemente, suas expressões (como a ciência e a filosofia) também o são. Koyré percebera, destarte, que, em sendo histórica a razão, mais mudanças (inclusive radicais), cortes, rupturas poderiam ocorrer no interior da esfera científica, levando a física clássica a outros estágios. Dessa maneira, nossa tese é que o epistemólogo em questão, a partir de suas investigações sobre as origens da ciência moderna, considerando a ciência sobretudo como teoria, construto racional, e também a racionalidade como móvel, mutável, histórica, conclui que o progresso da ciência deve ser, necessariamente, descontínuo; sua história, inevitavelmente, rúptil. Em sendo histórica a racionalidade, com inerência de mutações, fissuras, a história da razão científica também deve ter por característica ser fissurada, descontínua.

Em suma, nada obstante Koyré tenha debruçado-se sobre as origens da ciência moderna, ele notou que sua gênese deu-se em virtude de uma grande mudança no ideário filosófico daquela época, sobrevalendo um quadro de ideias científicas (moderno) em detrimento de outro (antigo e medieval). A disputa travada entre cientistas modernos e pré-modernos constitui-se como uma ilustração notória da mutabilidade da razão, da sua historicidade. A matematização do mundo, o matematismo físico, constituiu-se com tal pujança que levou a efeito uma revolução nos padrões racionais, destacando a his- toricidade da razão. Ademais, até o matematismo teve de ter uma condição pressuposta: uma mudança severa na concepção de mundo e de espaço, eclipsando-se o Cosmos dos antigos e medievais e exaltando o universo infinito dos modernos, imergindo o espaço como conjunto de lugares, hierarquicamente bem ordenado, e emergindo o espaço euclidiano tomado como real. A controvérsia referida (entre modernos e pré-modernos) e a transmutação do protótipo racional que ensejou deixaram claro, portanto, que era imanente à razão a ocorrência de modificações, mutações, da racionalidade, o que, com efeito, ocorrera algumas vezes, no interior do pensamento científico matematizado, por exemplo, com o advento das geometrias não-euclidianas dos matemáticos russo Nikolai Lobachevsky e alemão Bernhard Riemann e com as microfísicas do século XX. O filósofo francorruso notara que, nos séculos XVI e XVII, uma revolução filosófica acarretou uma revolução científica ou - como preferimos dizer - que a revolução científica dos séculos XVI e XVII foi também uma revolução filosófica.

\section{Conclusão}

$\mathrm{Na}$ "Introdução", expusemos nossa questão, situando-a: Koyré promovera, pioneiramente, uma epistemologia descontinuista. Ele o fizera tomando a revolução científica do século XVII como 
uma descontinuidade da razão científica. A ciência, conforme os positivistas e de acordo com o círculo meyersoniano, desenvolvia-se por acúmulo de conhecimento, sendo a física newtoniana um aprimoramento da cartesiana, a eisteiniana um prolongamento da newtoniana, etc., dado que sustentavam a existência de absolutos que formavam uma base comum dessas físicas. O francorruso, por sua vez, não adere à tese em favor dos absolutos, conferindo-lhes perecimento. Fazendo-os ruir, com a sua epistemologia, os absolutos, pôde sustentar que o solo, o alicerce dessas físicas é movediço, variando suas bases, quanto mais o restante. Dessa forma, consolidou a descontinuidade. Entretanto, ainda assim inquerimos: com qual ciência a ciência moderna teria descontinuado, dado que a ciência tal qual a conhecemos é a moderna? Já ocorrera aí alguma descontinuidade na razão? Esse é o nosso ponto chave. Conforme entendiam muitos epistemólogos, entre os quais constam os positivistas, a inauguração da ciência deu-se no século XVII. Antes, não havia ciência, mas filosofia, pensamento mágico, misticismos, religião, que só atrapalharam o surgimento do pensamento científico. Koyré aborda a ciência, a filosofia e a religião como expressões da racionalidade. É com a ciência e a filosofia antigas e medievais majoritária à época que a ciência moderna rompeu, mas não afirmando que antes só havia o irracional, crenças infundadas, mas promovendo um corte racional, salientando uma descontinuidade científica e filosófica de grandes proporções. Portanto, com a revolução científica do século XVII, já ocorrera uma ruptura na razão, posto que mudou-se a racionalidade e não do irracional para o racional. A ojeriza dos epistemólogos anteriores pela filosofia e religião agora se vê questionada, recebendo, de uma só vez, dois golpes do pensamento koyreano: (1) que atesta que filosofia, a teologia e até o pensamento mágico não tratam de questiúnculas especulativas, sendo também expressões da razão e exercendo, aliás, muita influência sobre a revolução científica do século XVII; (2) que frisa a gênese da ciência moderna como uma fissura na racionalidade, refratando a razão antiga e medieval (sobretudo aristotélica), hasteando novos padrões racionais.

$\mathrm{Na}$ primeira parte, apresentamos o conflito teórico entre o pensador francorruso e os epistemólogos positivistas, no qual aquele explica a ciência pelo primado da teoria e estes, pelo da técnica, empiria e pelo anseio prático, ativo da ciência moderna. Procuramos mostrar que os absolutos também perecem, que não há verdades eternas e que fundamentos vívidos por mais de um milênio podem virar escombros, pondo em relevo conflitos teóricos.

Na segunda parte, trouxemos à tona, apresentando-se como perecíveis os absolutos, a impossibilidade de considerarmos a razão como imóvel, avessa a 
quaisquer mutações internas, refratária a transformações nos princípios racionais. Pelo contrário, qualquer epistemologia deve levar em conta a história, haja vista a racionalidade ser histórica, mudar de tempos em tempos. Portanto, como a razão tem sua historicidade, marcada por cortes, a epistemologia tem de ser descontinua.

$\mathrm{Na}$ terceira parte, em compromisso com a clareza e com o pensamento de Koyré, pusemos em tela a explicação koyreana da emergência da ciência moderna. Segundo o historiador-filósofo, o que marca, superficialmente, a revolução supracitada é o matematismo, entendido como poder criativo da matemática e não como poder quantificador do real. A grande revolução teórica foi, deveras, a matematização do mundo. Mas, o que possibilitou tal matematização, característica primordial da ciência a partir da física clássica? Ora, de certo, o que foi o pressuposto da citada matematização, o que a tornou possível, configura-se como o mais profundo, o traço mais tenaz, da revolução. Trata-se da substituição do espaço aristotélico, um espaço empírico, compreendido como um conjunto de lugares, pela ideia de universo infinito, sem hierarquia ontológica e coincidente com o espaço da geometria euclidiana. Não há mais mundos regidos por distintas leis; mundo sublunar e supralunar fundemse, formando um todo homogêneo. Os corpos pesados, agora, podem ser pensados em um espaço cujas forças que atuam sobre eles são controladas por raciocínios. Doravante, pôde-se raciocinar de outra forma, pensando corpos em um espaço matemático, com esses, inclusive, adotando certas características dos entes matemáticos.

Enfim, na quarta e última parte do nosso artigo, respondemos à questão apresentada na "Introdução", mostrando que a revolução científica do século XVII foi um dos rompimentos racionais cujas consequências configuraram-se entre as mais importantes. Imponente, tal revolução exarou, profundamente, novas bases racionais. Explicamos, em linhas gerais, que Koyré abarcou como racionais e até científicas áreas do saber lançadas ao ostracismo da irracionalidade, da crença, da superstição e da especulação sem fundamento e irregrada. Daí, tornou-se possível demonstrar que a revolução científica do século XVII deuse em rompimento com ideias pertencentes a diversos campos do saber; daí, o historiador-filósofo pôde apresentar a revolução científica promulgada por Galileu e Descartes como uma ruptura interna da racionalidade, porque se aqueles pensamentos pré-modernos são racionais assim como a ciência moderna, romper com eles é refratar outra racionalidade, que não deixar de ser uma racionalidade por ser outra. Pondo na esfera da razão tais esferas do pensamento, a filosofia koyreana trabalha com a ideia de que toda revolução científica tem como pano de fundo uma am- 
biência teórica, gestada pela ciência, filosofia, religião, teologia e até pelo pensamento místico ou mágico. Doravante, gizar até onde vai a filosofia no campo científico e vice-versa mostra-se como uma tarefa intangível. Suas fronteiras não são tão claras. Até certo ponto, po- demos distinguir, de fato, muito bem a filosofia da religião e estas duas da ciências. Mas, enquanto pertencerem ao campo da razão, umas influenciarão as outras. O terreno da razão é, assim entendido, múltiplo e dinâmico, tanto em áreas quanto em princípios.

\section{Referências}

BACHELARD, Gaston. A formação do espírito científico: contribuição para uma psicanálise do conhecimento. Tradução de Estela dos Santos Abreu. Rio de Janeiro: Contraponto, 1996.

BERGÉ, Pierre; POMEAU, Yves; DUBOIS-GANCE, Monique. Dos Ritmos ao Caos. Tradução de Roberto Leal Ferreira. São Paulo: Editora UNESP, 1996.

BLANCHÉ, Robert. A Ciência Actual e o Racionalismo. Tradução de Maria José Andrade. Porto: Rés, 1983.

BULCÃO, Marly. O Racionalismo da Ciência Contemporânea: Uma Análise da Epistemologia de Gaston Bachelard. Rio de Janeiro: Edições Antares, 1981.

. “Uma reflexão sobre a concepção de história das ciências: Koyré e seus contemporâneos”. In: SALOMON, Marlon Jeison (org.). Alexandre Koyré. Historiador do Pensamento. Goiânia: Almeida Clément Edições, 2010.

COTTINGHAM, John. Dicionário Descartes. Tradução: Helena Martins. Rio de Janeiro: Zahar, 1995.

DESCARTES, René. Meditações sobre Filosofia Primeira. Coleção Multilíngues de Filosofia. Tradução: Fausto Castilho. Campinas: Editora da UNICAMP, 2013.

Oeuvres de Descartes. Vol. I. Ed. de Ch. Adam P. Tannery. Paris: Vrin, 1897.

Princípios da Filosofia. Tradução de João Gama. Lisboa: Edições 70, 1997.

FERREIRA, Fábio. "Alexandre Koyré e o Pensamento Científico". In: SALOMON, Marlon Jeison (org.). Alexandre Koyré: Historiador do Pensamento. Goiânia: Almeida e Clément Edições, 2010.

FRIAÇA, Amâncio. "Cronos e Cosmos". Ciência e Cultura, São Paulo, 2002, v. 54, n. 2, pp. 37-40. Disponível em $<$ http://cienciaecultura.bvs.br/pdf/cic/v54n2/14811.pdf> acessado em [14/01/2020].

GAULT, Jean Louis. "O nascimento da ciência moderna. Uma leitura de 'A ciência e a verdade”". Arquivos Brasileiros de Psicologia, Rio de Janeiro, 2015, v. 67, n. 2, pp. 156-161.

Disponível em <http://pepsic.bvsalud.org/pdf/arbp/v67n2/12.pdf $>$ acessado em [16/01/2020].

IANNINI, Gilson. "A estrutura e seus efeitos: o simbólico de Lévi-Strauss a Lacan, via Koyré”. Coringa, Belo Horizonte, 2011, n. 32, pp. 117-132.

KANT, Immanuel. Crítica da Razão Pura. Tradução de Valerio Rohden e Udo Baldur Moosburger. São Paulo: Editora Nova Cultura Ltda, 1999.

KOYRÉ, Alexandre. "As etapas da cosmologia científica". In: Estudos de História do Pensamento Científico. Tradução de Maria de Lourdes Menezes. Rio de Janeiro: Forense Universitária, 2011a.

"As origens da ciência moderna: uma nova interpretação". In: Estudos de História do Pensamento Científico. Tradução de Maria de Lourdes Menezes. Rio de Janeiro: Forense Universitária, 2011 b.

. "Da influência das concepções filosóficas sobre a evolução das teorias científicas". In: Estudos de História do Pensamento Filosófico. Tradução de Márcio Ramalho. Rio de Janeiro: Forense Universitária, 2011c.

. Do Mundo Fechado ao Universo Infinito. Tradução de Donaldson M. Garschagen. Rio de Janeiro: Forense Universitária, 2006.

. Études Galiléennes. Paris: Hermann, 1966.

"Galileu e a revolução científica do século XVII". In: Estudos de História do Pensamento Científico. Tradução de Maria de Lourdes Menezes. Rio de Janeiro: Forense Universitária, $2011 \mathrm{~d}$.

. "Galileu e Platão". In: Estudos de História do Pensamento Científico. Tradução de Maria de Lourdes Menezes. Rio de Janeiro: Forense Universitária, 2011e.

"Uma experiência de medida". In: Estudos de História do Pensamento Científico. Tradução de Maria de Lourdes Menezes. Rio de Janeiro: Forense Universitária, 2011f.

LIMA, Cláudia Henschel de; FERREIRA, Marcio Ramos. "Lacan com Koyré: teoria do sujeito e suas incidências clínicas". Arquivos Brasileiros de Psicologia, Rio de Janeiro, 2015, v. 67, n. 1, pp. 37-50.

Disponível em <http://pepsic.bvsalud.org/pdf/arbp/v67n1/04.pdf > acessado em [16/01/2020]. 
MOLES, Abraham A. A criação científica. Tradução de Gita K. Guinsburg. São Paulo: Perspectiva, 2010.

SALOMON, Marlon Jeison. "Alexandre Koyré e o nascimento da ciência moderna” in. SALOMON, Marlon Jeison (org.). Alexandre Koyré. Historiador do Pensamento. Goiânia: Almeida Clément Edições, 2010.

. "Entre história das ciências e das religiões: o problema da temporalidade histórica em Lucien Febvre e Alexandre Koyré no entreguerras". História da Historiografia, Ouro Preto, n. 19, 2015, p. 107-123. Disponível em $<$ https://www.historiadahistoriografia.com.br/revista/article/view/943/598> acessado em [10/01/2020].

. "Entre museus e cemitérios, entre monstros e fantasmas: a história das ciências em Gaston Bachelard e Alexandre Koyré”. Anais Eletrônicos XXVI Simpósio ANPUH, São Paulo, 2011.

Disponível em <http://www.snh2011.anpuh.org/resources/anais/14/1300880942_ARQUIVO_Bachelard,Koyremuseusecemiterios.pdf $>$ : acessado em [25/12/202019].

. "O problema do pensamento outro em Alexandre Koyré e Lucien Febvre". História da Historiografia, Ouro Preto, n. 15,2014 , p. 124-147.

Disponível em <https://www.historiadahistoriografia.com.br/revista/article/view/715/470 $>$ acessado em [11/0$1 / 2020]$.

Recebido: $29 / 01 / 2020$

Aprovado: $13 / 07 / 2020$

Publicado: $30 / 12 / 2020$ 
